\title{
Body Image and Body Composition: Comparisons of Young Male Elite Soccer Players and Controls
}

\author{
Marta Arroyo, José Manuel González-de-Suso, Celia Sanchez, \\ Laura Ansotegui, and Ana M. Rocandio
}

\begin{abstract}
The purpose of this study was to evaluate body composition and body image (perception and satisfaction) in a group of young elite soccer players and to compare the data with those of a control group (age and BMI matched). Participants were 56 volunteer males whose mean age and BMI were $19.6\left(S D\right.$ 1.3) years and $23.3(S D 1.1) \mathrm{kg} / \mathrm{m}^{2}$, respectively. Results showed that soccer players have a higher lean mass and lower fat mass than controls. Moreover, body perception (difference between current and actual image) was more accurate in controls than in soccer players, and the results suggest a tendency for soccer players to aspire to have more muscle mass and body fat. Soccer players perceived an ideal image with significantly higher body-fat percentage than their current and actual images. There were no body-dissatisfaction differences between groups, however. Although the results are necessarily limited by the small sample size, the findings should be of interest to coaches of young elite soccer teams.
\end{abstract}

Keywords: anthropometry, body-image perception, body-image satisfaction, university students

Body composition, anthropometric dimensions, and morphological characteristics play a vital role in determining the success of a soccer player (Keogh, 1999; Silvestre, West, Maresh, \& Kraemer, 2006). These parameters are sensitive indicators of the growth progress and nutritional status of a population that are ultimately relevant to a specific event in which the participants excel. Proper evaluation of these parameters reflects the quantification of the body's major structural components, which are required in different proportions for various sports to achieve excellence and which influence the selection of soccer players (Gil, Ruiz, Irazusta, Gil, \& Irazusta, 2007).

Such a detailed body assessment is a fundamental, yet frequently overlooked, standpoint from which subsequent assessment of body image can proceed. As "an evaluation of body size, weight, or any other aspect of the body that determines

Arroyo, Sanchez, Ansotegui, and Rocandio are with the Dept. of Nutrition and Food Science, University of the Basque Country, 01006 Vitoria-Gasteiz, Spain. González-de-Suso is with the Sports Medicine Dept., Real Sociedad de Fútbol SAD, Donostia-San Sebastián, Spain. 


\section{IJSNEM GALLEY PROOF}

physical appearance" (Thompson, 1990), body image can be viewed as the fulcrum of the mutual influences of physique, exercise, and dietary behavior on one another. It is a determinant of self-esteem and includes perceptual, cognitive, and affective elements, which are based partly on the construction of an objective anthropometric representation (Kay, 1996).

Several recent studies have found that athletes were better able to perceive body dimensions than nonathletes (Stewart, Benson, Michanikou, Tsiota, \& Narli, 2003) and that athletes reported a more positive body image than control groups (Hausenblas \& Downs, 2001). This result might be because athletes, because of their high physical activity levels, might more closely resemble the current aesthetic ideal of thin/lean and fit physique for females and a lean and muscular physique for males than do nonathletes (Brownell, 1991). This finding might also be a result of the fact that physical activity participation is associated with an increase in positive psychological characteristics (e.g., increased self-esteem, decreased mood disturbance) that are related to positive body image (Fox, 2000; Landers \& Arent, 2001). Most of this research has been done in women, however, and little is known about the effect of physical activity on body image in males. Moreover, few studies have assessed body composition to examine the moderating effects of body image in athletes.

The current study was therefore focused on evaluating the body composition and body image (perception and satisfaction) of a group of young soccer players and a control group and to compare them. We hypothesized that the soccer players would have better perception and lower dissatisfaction with their body image than the control group.

The study took into account the problems with using body-mass index (BMI) and percentage body fat $(\% \mathrm{BF})$ in research with athletes (Huddy, Nieman, \& Johnson, 1993). As a result, it used the fat-free-mass index (FFMI) because groups of athletic men, although potentially similar in \%BF, can differ considerably in levels of muscularity. The FFMI is a measure of muscularity derived from height, weight, and \%BF (Kouri, Pope, Katz, \& Oliva, 1995).

\section{Methods}

\section{Participants}

Participants were 56 male volunteers from the academy of a professional soccer team $(n=28)$ and from the University of the Basque Country (control group, $n=$ 28) whose mean age and BMI were, respectively, $19.6 \pm 1.3$ years and $23.3 \pm 1.1$ $\mathrm{kg} / \mathrm{m}^{2}$.

The group of elite young soccer players included 4 external defenders, 5 central defenders, 6 central midfielders, 4 external midfielders, 6 forwards, and 3 goalkeepers. The soccer players carried out 12-14 hr/week of training divided into 6 days, including technical, tactical, and physical training programs. All players were free from any illness and were not taking any medication. All athletes denied using anabolic agents.

Soccer players' data were compared with age- and BMI-matched control participants. Controls were university students participating in a study designed to 


\section{IJSNEM GALLEY PROOF}

assess their nutritional status. From a total population of 62 men, 28 were drawn to match the players in age and BMI. The control group was also free from any illness and was not taking any medication. They engaged in recreational sport activities such as swimming or soccer (in all cases $<3 \mathrm{hr} /$ week) that were not part of any competitive sport training.

Participants provided written informed consent, and the study was approved by the university Ethical Committee on Human Research. Participants completed a questionnaire that included basic information, along with items querying selfreported weight and height and ideal weight. The physical characteristics and selfreported and ideal variables of the participants are summarized in Table 1.

\section{Body-Composition Assessment}

Nine anthropometric measurements were taken: weight, height, and six skinfold thicknesses (subscapular, abdominal, suprailiac, midaxillary, chest, thigh, and triceps). A well-trained anthropometrist made the measurements in duplicate after marking the corresponding anthropometric points on the right side of the participant in accordance with Ross and Marfell-Jones (1991).

The measuring instruments employed were a scale stadiometer with a precision of $100 \mathrm{~g}$ and $1 \mathrm{~mm}$, a skinfold caliper with a precision of $0.2 \mathrm{~mm}$ (Holtain Ltd., Crymych, UK), and a Harpenden anthropometric tape. The measurements in the soccer players' group were made at the end of football season.

BMI was calculated using the formula weight $(\mathrm{kg}) / \mathrm{height}^{2}\left(\mathrm{~m}^{2}\right)$. Current BMI refers to BMI calculated using measured weight and height. Self-reported weight and height were obtained via questionnaire ("How much do you weigh without clothes and shoes?" and "How tall are you without shoes?"), and to assess ideal weight participants were asked "Ideally, how much would you like to weigh?"

Body density was calculated using the equations of Jackson and Pollock (1978; seven skinfolds), and the body density was converted to \%BF using Siri's (1961) equation. The software used to assess body image includes the formula of Jackson and Pollock (1978), as well. The results of \% BF of controls were interpreted using the classification of Bray, Bouchard, and James (1988). The \%BF of soccer players was classified according to the male \%BF chart of Jackson and Pollock (1977).

\section{Table 1 Physical Characteristics and Self-Reported and Ideal Variables of the Participants, $M \pm S D$}

\begin{tabular}{lccc}
\hline Variable & Soccer players & Control group & $\boldsymbol{p}$ \\
\hline Age $($ years $)$ & $19.5 \pm 1.3$ & $19.7 \pm 1.4$ & NS \\
Height $(\mathrm{cm})$ & $179.1 \pm 6.5$ & $177.4 \pm 4.9$ & NS \\
Weight $(\mathrm{kg})$ & $74.6 \pm 5.8$ & $73.3 \pm 6.1$ & NS \\
Body-mass index $\left(\mathrm{kg} / \mathrm{m}^{2}\right)$ & $23.3 \pm 1.0$ & $23.3 \pm 1.1$ & NS \\
Self-reported weight $(\mathrm{kg})$ & $74.5 \pm 5.7$ & $74.7 \pm 6.0$ & NS \\
Self-reported height $(\mathrm{cm})$ & $179.0 \pm 6.5$ & $178.5 \pm 4.9$ & NS \\
Ideal weight $(\mathrm{kg})$ & $74.2 \pm 5.7$ & $74.1 \pm 5.5$ & NS \\
\hline
\end{tabular}




\section{IJSNEM GALLEY PROOF}

\section{Body-Image Assessment}

After the anthropometric measurements, each participant took the somatomorphic matrix test (Pope, Phillips, \& Olivardia, 2000). The male version of the test contains a computerized library of 100 images of men, arranged in a $10 \times 10$ matrix, representing 10 degrees of fatness and 10 degrees of muscularity. A graphic artist constructed the images using reference photographs of actual men. On the fatness axis, the images begin at a $\% \mathrm{BF}$ of $4 \%$ (approximately the minimum figure attainable in men) and increase in steps of $4 \%$ to a maximum of $40 \%$ (a very obese man). On the axis of muscularity, the images are calibrated on the basis of FFMI. The images begin at an FFMI of $16.5 \mathrm{~kg} / \mathrm{m}^{2}$ and increase in steps of $1.5 \mathrm{~kg} / \mathrm{m}^{2}$ to a maximum FFMI of $30.0 \mathrm{~kg} / \mathrm{m}^{2}$.

The computer poses four standard questions: (a) "Choose the image that best represents your own body" (actual image), (b) "choose the image that represents the body that you ideally would like to have" (ideal image), (c) "choose the image that represents the body of an average man of your age" (average image), and (d) "choose the image that represents the body most desired by the opposite sex" (attractive image). It should be noted that this last question was asked regardless of the participant's sexual orientation, but in the current study all of the participants were heterosexual.

In each case, the participant scrolls through the images until he has chosen the image that he feels best answers the question. At that point, he clicks a button titled "select this image." The computer then stores his answer to the question, restores the image to the screen, and poses the next question in the series.

Thus, for each participant, we obtained five measurements: his actual body fat and muscularity (as expressed by FFMI), his perception of what he thought his fat and muscularity were, the level of fat and muscularity that he ideally wished to have, his judgment of the level of fat and muscularity of an average man of his age in his society, and his judgment of the level of fat and muscularity of the male body that women would prefer.

Studies on body image frequently assume that the difference between actual and ideal image provides a valid measurement of body-image dissatisfaction (Thompson, Heinberg, Altabe, \& Tantleff-Dunn 1998). The differences between actual and ideal FFMI and between actual and ideal \%BF were estimated. The positive differences were interpreted as dissatisfaction for exceeding and the negative differences as dissatisfaction by default.

The degree of dissatisfaction was measured with four categories based on the classification of Casillas-Estrella, Montaño-Castrejón, Reyes-Velázquez, Barcardi-Gascón, and Jimenéz-Cruz (2006) and the increases for FFMI $\left(1.5 \mathrm{~kg} / \mathrm{m}^{2}\right)$ and for $\% \mathrm{BF}(4 \%)$ between images in the somatomorphic matrix test (Pope et al., 2000). We considered the participant satisfied when the difference between actual and ideal image was 0 . The other categories were 1 , slight dissatisfaction (difference between actual and ideal FFMI $=1.5 \mathrm{~kg} / \mathrm{m}^{2}$, difference between actual and ideal $\% \mathrm{BF}=4 \%$ ); 2 , medium dissatisfaction (difference between actual and ideal $\mathrm{FFMI}=3.0 \mathrm{~kg} / \mathrm{m}^{2}$, difference between actual and ideal $\% \mathrm{BF}=8 \%$ ); and 3 , severe dissatisfaction (difference between actual and ideal FFMI $\geq 4.5 \mathrm{~kg} / \mathrm{m}^{2}$, difference between actual and ideal $\% \mathrm{BF} \geq 12 \%$ ). 


\section{IJSNEM GALLEY PROOF}

Body Image and Composition in Soccer Players

\section{Statistical Analysis}

All results were expressed as $M \pm S D$. The distribution of quantitative variables was tested for normality using the Kolmogorov-Smirnov test with the Lilliefors correction to apply a parametric or nonparametric test for groups comparison. The differences between independent samples were analyzed using Student's $t$ test and the Mann-Whitney $U$ test. The differences between related samples (individual data) were analyzed using Student's $t$ test and the Wilcoxon test. Chi-square analysis was used to calculate the significance of differences between the participants' ratings of body-image dissatisfaction. Alpha level for all of these analyses was set at $p<.05$ (two-tail test). Data were analyzed using SPSS 13.0 (SPSS Inc., Chicago, IL, USA).

\section{Results}

An examination of the self-reported and ideal data indicated that $21.4 \%$ of players and $17.9 \%$ of control participants desired a higher weight. The discrepancy between ideal and current weight indicated that there were not significant differences between groups in the desire for weight gain or weight loss $(p>.05)$. Significant differences were observed between self-reported and current weight in the control group (difference: $1.4 \pm 1.9 \mathrm{~kg} ; p<.01$ ). This difference in the players' group, however, was not significant (difference: $-0.1 \pm 0.4 \mathrm{~kg} ; p>.05$ ).

Significant group differences were observed for current \%BF and FFMI $(p<$ .001). Young elite soccer players had a higher FFMI than the control group. The control group had a higher $\% \mathrm{BF}$ than the soccer players $(p<.001$; Table 2$)$. There were, however, no differences between groups in the perceived image in $\% \mathrm{BF}(p$

Table 2 Current Measurements and Perceived, $M \pm S D$

\begin{tabular}{lccc}
\hline & Soccer players & Control group & $\boldsymbol{p}$ \\
\hline $\begin{array}{l}\text { Body fat }(\%) \\
\text { current }\end{array}$ & $7.6 \pm 1.7$ & $12.3 \pm 3.1$ & $<.01$ \\
image & & & \\
$\quad$ actual & $14.7 \pm 6.5$ & $18.0 \pm 5.1$ & $\mathrm{NS}$ \\
$\quad$ ideal & $17.3 \pm 4.6$ & $17.4 \pm 3.5$ & $\mathrm{NS}$ \\
$\quad$ average & $19.6 \pm 5.6$ & $19.0 \pm 3.7$ & $\mathrm{NS}$ \\
$\quad$ attractive & $17.3 \pm 3.6$ & $16.0 \pm 4.8$ & $\mathrm{NS}$ \\
Fat-free-mass index $\left(\mathrm{kg} / \mathrm{m}^{2}\right)$ & & & \\
current & $21.3 \pm 0.9$ & $20.2 \pm 0.7$ & $<.001$ \\
image & & & \\
$\quad$ actual & $20.6 \pm 1.9$ & $20.4 \pm 1.4$ & $\mathrm{NS}$ \\
$\quad$ ideal & $23.0 \pm 2.2$ & $22.1 \pm 1.7$ & $\mathrm{NS}$ \\
$\quad$ average & $19.6 \pm 1.6$ & $21.4 \pm 1.5$ & $<.001$ \\
$\quad$ attractive & $23.5 \pm 1.7$ & $24.0 \pm 1.4$ & $\mathrm{NS}$ \\
\hline
\end{tabular}




\section{IJSNEM GALLEY PROOF}

$>$.05) and in all the measurements of the perceived image in the FFMI, apart from the average image, with the soccer players perceiving smaller body size than the controls.

According to the classification for $\% \mathrm{BF}$, in the control group $39.3 \%$ had lower than normal values and the rest $(60.7 \%)$ were inside the normal range. In the players' group, $3.6 \%$ were classified as lean, $67.9 \%$ as ideal, and $28.6 \%$ as average. As for position on the team, three groups of players (defenders, midfielders, and forwards) had similar body composition (Table 3 ).

Differences in perceived FFMI were observed between ideal and average image in the soccer players' group $(p<.001)$ and between ideal and attractive image in the control group ( $p<.001$; Table 4$)$. Soccer players perceived the average image with significantly lower FFMI than their current, actual, ideal, or attractive image $(p<.001)$. Moreover, both soccer players and controls perceived the ideal, average, and attractive images with significantly higher $\% \mathrm{BF}$ than their actual image (Table 5), but these differences were higher in players than in controls $(p<.001)$.

Regarding body-image dissatisfaction, $78.5 \%$ of players and $82.2 \%$ of controls were dissatisfied with respect to their muscularity (Table 6). Although these results were not statistically significant, more soccer players than control participants showed severe dissatisfaction, and in the control group more individuals showed a slight dissatisfaction with their FFMI (Table 7). There were no differences in dissatisfaction observed for \%BF between groups. Some $64.3 \%$ of players and the same percentage of controls were dissatisfied with their $\% \mathrm{BF}$.

\section{Discussion}

The current study compared different body-composition indicators between a group of soccer players and a control group. The age, weight, and height of the soccer players were within the range of values reported by other authors (Casajús \& Aragonés, 1991; González \& Andrés, 1996). \%BF, however, was lower than values published in different studies of teams from the same category (Reilly, 1996; Silvestre et al., 2006) and similar to the results of other authors (Alburquerque, Sánchez, Pietro, Lopez, \& Santos, 2005; Pellenc \& Costa, 2006). Rico-Sanz et al. (1998) stated in their review that soccer players should have a \%BF of around $10 \%$, and this is higher than our results. We would have to question whether the comparison of $\% \mathrm{BF}$ was valid, because the cited studies used different equations.

\section{Table 3 Body Composition of the Football (Soccer) Players According by Playing Position, $M \pm S D$}

\begin{tabular}{lcc}
\hline Playing position & Body fat $(\%)$ & Fat-free-mass index $\left.\mathbf{( k g} / \mathbf{m}^{2}\right)$ \\
\hline Defender $(n=9)$ & $7.3 \pm 1.6$ & $21.2 \pm 0.7$ \\
Midfielder $(n=10)$ & $7.7 \pm 1.9$ & $20.9 \pm 0.9$ \\
Forward $(n=6)$ & $7.8 \pm 2.0$ & $22.0 \pm 0.7$ \\
Goalkeeper $(n=3)$ & $7.6 \pm 0.8$ & $21.7 \pm 0.7$ \\
\hline
\end{tabular}




\section{IJSNEM GALLEY PROOF}

Body Image and Composition in Soccer Players

Table 4 Differences Between Current Measurements of Fat-FreeMass Index $\left(\mathrm{kg} / \mathrm{m}^{2}\right)$ and Perceived, $M \pm S D$

\begin{tabular}{lccc}
\hline & Soccer players & Control group & $\boldsymbol{p}$ \\
\hline Current image - actual image & $0.7 \pm 1.8^{*}$ & $-0.2 \pm 1.5$ & $<.05$ \\
Current image - ideal image & $-1.7 \pm 2.4^{* *}$ & $-1.9 \pm 1.9 * * *$ & $\mathrm{NS}$ \\
Current image - average image & $1.8 \pm 2.0^{* * *}$ & $-1.2 \pm 1.6^{* *}$ & $<.001$ \\
Current image - attractive image & $-2.2 \pm 2.1 * * *$ & $-3.8 \pm 1.8^{* * *}$ & $<.01$ \\
Actual image - ideal image & $-2.4 \pm 1.7 * * *$ & $-1.8 \pm 1.2 * * *$ & $\mathrm{NS}$ \\
Actual image - average image & $1.0 \pm 1.8^{* *}$ & $-1.0 \pm 1.9 * *$ & $<.001$ \\
Actual image - attractive image & $-2.9 \pm 1.9 * * *$ & $-3.6 \pm 1.7 * * *$ & $\mathrm{NS}$ \\
Ideal image - average image & $3.4 \pm 2.2^{* * *}$ & $0.8 \pm 2.1 *$ & $<.001$ \\
Ideal image - attractive image & $-0.5 \pm 1.9$ & $-1.8 \pm 1.8 * * *$ & $<.05$ \\
Average image - attractive image & $-3.9 \pm 2.0 * * *$ & $-2.6 \pm 2.0 * * *$ & $<.001$ \\
\hline
\end{tabular}

Level of significance in the group: ${ }^{*} p<.05 . * * p<.01 . * * * p<.001$.

\section{Table 5 Differences Between Current Measurements of Body Fat} (\%) and Perceived, $M \pm S D$

\begin{tabular}{lccc}
\hline & Soccer players & Control group & $\boldsymbol{p}$ \\
\hline Current image - actual image & $-7.2 \pm 6.4 * * *$ & $-5.7 \pm 4.8^{* * *}$ & NS \\
Current image - ideal image & $-9.7 \pm 4.5^{* * *}$ & $-5.1 \pm 3.7 * * *$ & $<.001$ \\
Current image - average image & $-12.0 \pm 6.1 * * *$ & $-6.7 \pm 4.4 * * *$ & $<.001$ \\
Current image - attractive image & $-9.7 \pm 3.7 * * *$ & $-3.7 \pm 6.2^{* *}$ & $<.001$ \\
Actual image - ideal image & $-2.6 \pm 6.4 *$ & $0.6 \pm 5.2$ & NS \\
Actual image - average image & $-4.9 \pm 7.3^{* *}$ & $-1.0 \pm 7.4$ & NS \\
Actual image - attractive image & $-2.6 \pm 6.5^{*}$ & $2.0 \pm 7.3$ & $<.05$ \\
Ideal image - average image & $-2.3 \pm 8.1$ & $-1.6 \pm 4.3$ & NS \\
Ideal image - attractive image & $0.0 \pm 3.9$ & $1.4 \pm 4.3$ & NS \\
Average image - attractive image & $2.3 \pm 7.2$ & $3.0 \pm 5.7$ & NS \\
\hline
\end{tabular}

Level of significance in the group: $* p<.05 . * * p<.01 . * * * p<.001$.

The body-composition study revealed, as expected, that the soccer players had significantly lower fat mass and significantly higher lean mass than age- and BMI-matched control participants. This is similar to findings reported by other authors (Bandyopadhyay, 2007; Wittich, Oliveri, Rotemberg, \& Mautalen, 2001).

There were no differences in body composition according to playing position in the soccer players. Authors investigating body fat in different playing positions in soccer (Reilly, 1996) found small differences in \%BF among the outfield positions, although midfielders tended to have lower body-fat levels. Midfield is a position in which players spend most of their time running and sprinting and 


\section{Table 6 Differences Between Actual and Ideal Image in the Soccer} Players' Group, $M \pm S D$

\begin{tabular}{lccc}
\hline & & \multicolumn{2}{c}{ Difference $^{\mathrm{a}}$} \\
\cline { 3 - 4 } & Total & Positive & Negative \\
\hline Fat-free-mass index & & & \\
$0($ difference $=0)$ & $6 \% \pm 21.4 \%$ & & $6 \% \pm 21.4 \%$ \\
$1\left(\right.$ difference $\left.=1.5 \mathrm{~kg} / \mathrm{m}^{2}\right)$ & $6 \% \pm 21.4 \%$ & & $10 \% \pm 35.7 \%$ \\
$2\left(\right.$ difference $\left.=3.0 \mathrm{~kg} / \mathrm{m}^{2}\right)$ & $10 \% \pm 35.7 \%$ & & $6 \% \pm 21.4$ \\
$3\left(\right.$ difference $\left.\geq 4.5 \mathrm{~kg} / \mathrm{m}^{2}\right)$ & $6 \% \pm 21.4$ & & \\
Body fat $\%$ & & & $4 \% \pm 14.3 \%$ \\
$0($ difference $=0)$ & $10 \% \pm 35.7 \%$ & & $3 \% \pm 10.7 \%$ \\
$1($ difference $=4 \%)$ & $10 \% \pm 35.7 \%$ & $6 \% \pm 21.4 \%$ & \\
$2($ difference $=8 \%)$ & $5 \% \pm 17.9 \%$ & $1 \% \pm 3.6 \%$ & \\
$3($ difference $\geq 12 \%)$ & $3 \% \pm 10.7 \%$ & & \\
\hline
\end{tabular}

aThe positive differences were interpreted as dissatisfaction for exceeding and the negative differences as dissatisfaction by default.

\section{Table 7 Differences Between Actual and Ideal Image in the Control} Group, $M \pm S D$

\begin{tabular}{lccc}
\hline & & \multicolumn{2}{c}{ Difference $^{\mathrm{a}}$} \\
\cline { 3 - 4 } & Total & Positive & Negative \\
\hline Fat-free-mass index & & & \\
$0($ difference $=0)$ & $5 \% \pm 17.9 \%$ & & $14 \% \pm 50.0 \%$ \\
$1\left(\right.$ difference $\left.=1.5 \mathrm{~kg} / \mathrm{m}^{2}\right)$ & $14 \% \pm 50.0 \%$ & & $8 \% \pm 28.6 \%$ \\
$2\left(\right.$ difference $\left.=3.0 \mathrm{~kg} / \mathrm{m}^{2}\right)$ & $8 \% \pm 28.6 \%$ & & $1 \% \pm 3.6 \%$ \\
$3\left(\right.$ difference $\left.\geq 4.5 \mathrm{~kg} / \mathrm{m}^{2}\right)$ & $1 \% \pm 3.6 \%$ & & \\
Body fat $\%$ & & & \\
$0($ difference $=0)$ & $10 \% \pm 35.7 \%$ & & $2 \% \pm 17.9 \%$ \\
$1($ difference $=4 \%)$ & $12 \% \pm 42.9 \%$ & $7 \% \pm 25.0 \%$ & \\
$2($ difference $=8 \%)$ & $4 \% \pm 14.3 \%$ & $4 \% \pm 14.3 \%$ & \\
$3($ difference $\geq 12 \%)$ & $2 \% \pm 7.1 \%$ & & \\
\hline
\end{tabular}

aThe positive differences were interpreted as dissatisfaction for exceeding and the negative differences as dissatisfaction by default.

cover more ground than their defensive and offensive teammates (Di Salvo et al., 2007).

Regarding the bias in self-reports of weight, the control group had larger differences than the soccer players. Control individuals said that they weigh more than their current weight $(p<.01)$. This difference in the soccer players' group was not significant, however, probably because they were weighed periodically. 


\section{IJSNEM GALLEY PROOF}

Body Image and Composition in Soccer Players

In addition, in the current study a difference between FFMI of the current and actual image was found in the soccer players' group $(p<.05)$, whereas in the control group it was not different. In contrast, other studies suggested that perception was better in athletes than in controls (Stewart et al., 2003).

The difference between ideal and average image suggests a difference in soccer players $(p<.001)$. Their ideal image had greater muscle mass than the image that represents the body of an average man of their age. This difference could be a result of the relation between muscularity and sports performance (Hoshikawa et al., 2006).

On the other hand, in the control participants differences were observed between ideal and attractive image $(p<.001)$, with the FFMI values being higher for the attractive image than for the ideal image. This result could be related to men's concept of masculinity (Pope et al., 2000). A variety of research has indicated a relationship between men's endorsement of traditionally masculine ideas and characteristics and his desire for additional muscle (McCreary, Saucier, \& Courtenay, 2005). Some research has suggested that this relationship between muscle mass and masculinity might begin early in life, because boys' action figures are often depicted as supermuscular, often beyond the limits of human physiology (Pope, Olivardia, Gruber, \& Borowiecki, 1999).

Regarding body fat, the number of controls classified as lower than normal $(39.3 \%)$ was higher than the number of soccer players classified as such $(3.6 \%)$. Soccer players perceived the ideal, average, and attractive images, however, with significantly higher \% BF than their actual image. There were no corresponding differences in the control group, but significant differences were found between groups in the difference between actual and attractive image for body fat $(p<.05)$. Soccer players perceived an image with higher body fat than their actual image as attractive, whereas controls considered an image with lower body fat than their actual image as attractive. This discrepancy between groups could be a result of body-image perception, because in soccer players the actual \%BF was much higher than their current $\% \mathrm{BF}$. Very little research has examined body-fat dissatisfaction in athletes, but most of them emphasized the desire not to gain fat (Choi, Pope, \& Olvardia, 2002; Yang, Gray, \& Pope, 2005). Our findings might also result from the fact that soccer players took the ideal image and average image together, instead of associating the ideal image with the value of $\% \mathrm{BF}$ recommended in athletic practice.

The results for body-image dissatisfaction revealed that there were not differences in either FFMI or \%BF between groups. Therefore the initial hypothesis (that the soccer players would have lower dissatisfaction with their body image than the control group) was not proved. Although the results for dissatisfaction with FFMI were not statistically significant, the soccer players' data suggested that more soccer players than control participants showed severe dissatisfaction, desiring greater muscle mass. This would support the contention that men's drive for muscle mass is unrelated to their actual level of muscle mass (McCreary, Karvinen, \& Davis, 2006).

In summary, the young elite soccer players in the current study had a higher lean mass and lower fat mass than the age- and BMI-matched control group. Moreover, body perception was better in controls than in soccer players, and the 


\section{IJSNEM GALLEY PROOF}

results suggest a tendency for players to aspire to have more muscle mass. There were, however, no body-dissatisfaction differences between groups.

Although the results are necessarily limited by the small sample size, the findings should be of interest to coaches of young elite soccer teams.

\section{Acknowledgment}

We thank all the participants and I. Hormaetxe and M.E. Díaz for their assistance.

\section{References}

Alburquerque, F., Sánchez, F., Pietro, J., Lopez, N., \& Santos, M. (2005). Kinanthropometric assessment on football team over one season. European Journal of Anatomy, 9, 17-22.

Bandyopadhyay, A. (2007). Anthropometry and body composition in soccer and volleyball players in West Bengal, India. Journal of Physiological Anthropology, 26, 501-505.

Bray, G., Bouchard, C., \& James, W.P.T. (1988). Definitions and proposed current classifications of obesity. In G. Bray, C. Bouchard, \& W.P.T. James (Eds.), Handbook of obesity (pp. 31-40). New York: Marcel Dekker.

Brownell, K.D. (1991). Dieting and the search for the perfect body: Where physiology and culture collide. Behavior Therapy, 22, 1-12.

Casajús, J.A.Y., \& Aragonés, M.T. (1991). Estudio cineantropométrico del futbolista de alto nivel. Composición corporal y somatotipo. Arch Med Deporte, 8, 147-151.

Casillas-Estrella, M., Montaño-Castrejón, N., Reyes-Velázquez, V., Barcardí-Gascón, M., \& Jiménez-Cruz, A. (2006). A mayor IMC mayor grado de insatisfacción de la imagen corporal. Rev Biomed, 17, 243-249.

Choi, P.Y.L., Pope, H.G., \& Olivardia, R. (2002). Muscle dysmorphia: A new syndrome in weightlifters. British Journal of Sports Medicine, 36, 375-388.

Di Salvo, V., Baron, R., Tschan, H., Calderon Montero, F.J., Bachl, N., \& Pigozzi, F. (2007). Performance characteristics according to playing position in elite soccer. International Journal of Sports Medicine, 28, 222-227.

Fox, K.R. (2000). The effects of exercise on self-perceptions and self-esteem. In S.J.H. Biddle, K.R. Fox, \& S.H. Boutcher (Eds.), Physical activity, mental health, and psychological well-being. London: Routledge \& Kegan Paul.

Gil, S., Ruiz, F., Irazusta, A., Gil, J., \& Irazusta, J. (2007). Selection of young soccer players in terms of anthropometric and physiological factors. Journal of Sports Medicine and Physical Fitness, 47, 25-32.

González, J.A., \& Andrés, M.J. (1996). Estudio fisiológico en jugadores de fútbol [Physiological study of football players]. Training Fútbol, 6, 38-43.

Hausenblas, H.A., \& Downs, D.S. (2001). Comparison of body image between athletes and nonathletes: A meta-analytic review. Journal of Applied Sport Psychology, 13, 323-339.

Hoshikawa, Y., Muratsu, M., Iida, T., Uchiyama, A., Nakajima, Y., Kanehisa, H., \& Fukunaga, T. (2006). Influence of the psoas major and thigh muscularity on 100-m times in junior sprinters. Medicine and Science in Sports and Exercise, 38, 2138-2143.

Huddy, D.C., Nieman, D.C., \& Johnson, R.L. (1993). Relationship between body image and percent body fat among college male varsity athletes and non-athletes. Perceptual and Motor Skills, 77, 851-857.

Jackson, A.S., \& Pollock, M.L. (1977). Prediction accuracy of body density lean body weight and total blood volume equations. Medicine and Science in Sports, 9, 197201. 


\section{IJSNEM GALLEY PROOF}

Body Image and Composition in Soccer Players

Jackson, A.S., \& Pollock, M.L. (1978). Generalized equations for predicting body density of man. The British Journal of Nutrition, 40, 497-504.

Kay, S. (1996). The psychology and anthropometry of body image. In K. Norton \& T. Olds (Eds.), Anthropometrica (pp. 236-258). Sydney, Australia: University of New South Wales Press.

Keogh, J. (1999). The use of physical fitness scores and anthropometric data to predict selection in an elite under-18 Australian Rules football team. Journal of Science and Medicine in Sport, 2, 125-133.

Kouri, E.M., Pope, H.G., Katz, D.L., \& Oliva, P.S. (1995). Fat-free mass index in users and non-users of anabolic-androgenic steroids. Clinical Journal of Sport Medicine, 5, 223-228.

Landers, D.M., \& Arent, S.M. (2001). Physical activity and mental health. In R.N. Singer, H.A. Hausenblas, \& C.M. Janelle (Eds.), Handbook of research on sport psychology (pp. 740-765). New York: John Wiley \& Sons.

McCreary, D.R., Karvinen, K., \& Davis, C. (2006). The relationship between the drive for muscularity and anthropometric measures of muscularity and adiposity. Body Image, $3,145-152$.

McCreary, D.R., Saucier, D.M., \& Courtenay, W.H. (2005). The drive for muscularity and masculinity: Testing the associations among gender role traits, behaviors, attitudes, and conflict. Psychology of Men \& Masculinity, 6, 83-94.

Pellenc, R.B., \& Costa, I.A. (2006). Comparación antropométrica en futbolistas de diferente nivel [Anthropometric comparison of different-level football players]. PubliCE Standard, Pid: 713.

Pope, H.G., Olivardia, R., Gruber, A., \& Borowiecki, J. (1999). Evolving ideals of male body image as seen through action toys. The International Journal of Eating Disorders, 26, 65-72.

Pope, H.G., Phillips, K.A., \& Olivardia, R. (2000). The Adonis complex. New York: Free Press.

Reilly, T. (1996). Fitness assessment. In T. Reilly (Ed.), Science and soccer (pp. 25-50). London: E \& FN Spon.

Rico-Sanz, J., Frontera, W.R., Mole, P.A., Rivera, M.A., Rivera-Brown, A., \& Meredith, C.N. (1998). Dietary and performance assessment of elite soccer players during a period of intense training. International Journal of Sport Nutrition, 8, 230-240.

Ross, W.D., \& Marfell-Jones, M.J. (1991). Kinanthropometry. In J.D. MacDougall (Ed.), Physiological testing of the high-performance athlete (2nd ed., pp. ). Canadian Associations of Sports Sciences, Sports Medicine Council of Canada.

Silvestre, R., West, C., Maresh, C.M., \& Kraemer, W.J. (2006). Body composition and physical performance in men's soccer: A study of a National Collegiate Athletic Association Division I team. Journal of Strength and Conditioning Research, 20, 177-183.

Siri, W.E. (1961). Body composition from fluid spaces and density: Analysis of methods. In J. Brozeck \& A. Henschel (Eds.), Techniques for measuring body composition (pp. 223-244). Washington, DC: National Academy of Sciences, Natural Resource Council.

Stewart, A.D., Benson, P.H., Michanikou, E.G., Tsiota, D.G., \& Narli, M.K. (2003). Body image perception, satisfaction and somatotype in male and female athletes and nonathletes: Results using a novel morphing technique. Journal of Sports Sciences, 21, $815-823$.

Thompson, J.K. (1990). Body image disturbance: Assessment and treatment. New York: Pergamon Press.

Thompson, J.K., Heinberg, L.J., Altabe, M., \& Tantleff-Dunn, S. (1998). Exacting beauty: Theory, assessment, and treatment of body image disturbance (pp. 8-12). Washington, DC: American Psychological Association. 
Wittich, A., Oliveri, M.B., Rotemberg, E., \& Mautalen, C. (2001). Body composition of professional football (soccer) players determined by dual X-ray absorptiometry. Journal of Clinical Densitometry, 4, 51-55.

Yang, C.F., Gray, P., \& Pope, H.G. (2005). Male body image in Taiwan versus the West: Yanggang Zhiqi meets the Adonis complex. The American Journal of Psychiatry, 162, 263-269. 
Author: Read proofs carefully. This is your only opportunity to make changes. No further alterations will be allowed after this point.

Author Queries

[AQ1]: Please provide a complete postal address for Gonzalez-de-Suso so that we can send him a copy of the issue on publication.

[AQ2]: Casajus ref: Please spell out the journal title and provide an English translation of the article title.

[AQ3]: Casillas-Estrella ref: Please spell out the journal title and provide an English translation of the article title.

[AQ4]: Pellenc ref.: Please provide more information. Exactly what sort of publication is this? Where was it published, and by whom?

[AQ5]: Ross ref.: Where was this published, city and province? Please provide the page range for the chapter. 